\title{
Investigation and analysis of Banoo Ghasseb's personality in Banoo Ghasseb letter system According to the theory of creative women from Estes
}

\section{Investigación y análisis de la personalidad de Banoo Ghasseb en el sistema de letras de Banoo Ghasseb Según la teoría de las mujeres creativas de Estes}

\section{Farahnaz Jalali Ghasempour}

PhD Student in Persian Language and Literature, Islamic Azad University, Mashhad Branch, Mashhad, Iran

\section{Reza Ashrafzadeh}

Member of the Department of Persian Language and Literature, Islamic Azad University, Mashhad Branch, Mashhad, Iran

\section{Batool Fakhr al-Islam}

Member of the Department of Persian Language and Literature, Islamic Azad

University, Mashhad Branch, Mashhad, Iran

*Correspondence

Email: farahnazjalalighasempour@gmail.com

\section{Cite as:}




\section{Summary}

In recent decades, various theories and movements have been formed regarding women and their role in human society, and a number of experts have sought to eliminate gender stereotypes arising from patriarchal culture. They have been identifying women. Among them is Clarissa Pincola Estes, who has taken an important step in achieving dignity for women with her theory of creative women. In the field of classical Persian literature, despite the dominance of patriarchal culture, in some cases we have witnessed the emergence of women who have broken social norms and tried to achieve an identity independent of men. Rostam Dokhtar's lady is one of these women whose thoughts and behaviors are mentioned in the's poem. In this research, with reference to library resources and descriptive-analytical method, as well as the use of components of the theory of creative women from Estes, the characteristics of Banu Ghasseb have been studied and described. The results show that this woman has an independent female personality and has made efforts to combat the culture of male monologue. His negative reaction to love and marriage to Gio, the killing of Tamratash Turani, the fight against Rustam and the Indian suitors are some of the manifestations of this effort. With complete selfknowledge, the use of creativity, as well as awareness of her physical abilities, she transforms feminine passivity and stagnation into dynamism, and with an unyielding spirit, a laudable attempt to eliminate the unfavorable life situations. Had. Creativity in Banoo Ghasseb's personality has two external (invention of needlework) and internal (resistance to authoritarian men).

Keywords: Patriarchy, Creative Women, Clarissa Pincola Estes.

\section{Introduction}

Clarissa Pinkola Estés is one of the psychotherapists affiliated with the Jung School of Psychology and is one of the leading and creative figures of the postwar period. She believes that by analyzing the stories of different lands and extracting and re-reading the hidden myths in it, it is possible to reach the hidden dimensions of female personality and recognize their inner world. The feedback of this achievement is the realization of the ways of gaining individuality and the flourishing of the neglected and repressed abilities of women. Also, from Estes' point of view, women reach a level of cognition that recognizes the obstacles and problems of reaching perfection and tries to solve them. What values Estes's views is her special attention to the Wild Women Archetype, the quality of which will have a profound effect on women's lives. To this end, he has used stories and legends from different cultures. The main purpose of this archetype, which is mainly reflected in the book Women Who Run with Wolves, is to validate the female personality and bring them to the stage of self-awareness and self-belief, regardless of the gender boundaries defined by Towards tradition and custom, to be encouraged for a desirable and useful presence in society and to play a more prominent role in the development of human civilization than before. In other words, Estes aims to achieve this 
goal by teaching women that by discovering and nurturing their inner talents, they will be able to eliminate their current disadvantages and ultimately build a better world than they do today. Attention to the intellectual development and quality of life of women is not limited to Western culture and contemporary knowledge, but in many Eastern cultures this issue has been more or less considered, given the position of women in Human societies seem obvious.

\section{Statement of the problem}

In the field of Persian literature, male creative personalities have a special appearance due to the dominant patriarchal discourse. Naturally, in the context of this discourse, women have a marginal and shadowy role, and the importance of their presence in society is not addressed as it should be. Hence, the women addressed in Persian literary texts are mostly static and uncreative and are considered the only means to achieve male goals. In such an intellectual space, a work has been created in which the main and pivotal character is a woman named Bano Gashsab. She is the daughter of the superhero Rostam, the heroic hero of Ferdowsi Shahnameh and the sister of Faramarz. Under Rostam's teachings, Banu Ghasseb has become a brave warrior and has emerged as a dynamic and praiseworthy figure in the monolithic and patriarchal world of Persian epics. So that only the Persian epic poem has been written in his name and in the description of his life and actions. However, in the cultural context of traditional Iranian society, women are considered the second sex for various reasons, and male hegemony has had a less favorable view of them. Many scholars consider this woman to be the objective and altered representation of female goddesses in mythology. (Karachi et al., 2005: 24; Riahi-e-Zamin and Jabar-eNaserou, 1390: 149) O has been written for him.

The main issue of the present study is the representation and explanation of the behavioral components of this heroine. To achieve this goal, Clarissa Pincola Estes' theory of creative women has been used to form the results of research based on sound and methodical theories. Also, the achievements of the leading article have a positive effect on introducing a worthy female model from Iranian culture and prove the richness of Persian epic literature. The main questions of this research are: a) What effect does the application of the theory of creative women from Estes have on the representation of Banoo Ghasseb's personality? B) What have been the most important reactions and actions of Banu Ghasseb to upset the situation resulting from patriarchal discourse? C) What effect did the archetype of the savage woman have on the attainment of individuality?

\section{Necessity and oh Research dead}

Women, as half of human society, have an effective role in the growth and excellence of human culture, and the prosperity of any society is tied to their role-playing in various events. Therefore, strategies must be considered so that women realize the importance of their position and strive to achieve individuality. Introducing the existing models in this field has an important role in achieving these goals. Introducing the character of Banu Goshsab as a woman who came from Iranian culture and in her heroic period, with 
conscious habituation and norm-breaking, has presented a different image of the traditional reading of society from the female sex, in encouraging women to tend to cognitive and personality changes. And expressing their capacities to achieve personality perfection and ascend to spiritual levels has a positive effect and will be useful in reforming the hegemonic and patriarchal view of women and appreciating the abilities of this section of society. In addition, it is possible to read the Lady of the Epic poem beyond the rules of the epic and with a new perspective.

Naturally, the use of scientific and methodical theories, such as the theory of creative women from Estes, is effective in consolidating analyzes that address various aspects of Banu Ghasseb's creative personality. Also, the secondary intentions and underlying layers of the author's goals are represented and explained from the composition of the work and the social context of the work, apart from its epic aspects.

\section{Research Methods}

In this research, descriptive-analytical method and library resources have been used. Creative theory of creative women has been used to validate the analysis. The general structure of the article is as follows: first, explanations about the basics of the mentioned theory are provided and then, in the main section, under various headings, Banoughasseb's feminine creations are represented. The statistical population of the research, the system of Banoo Ghasbeh, and the sample size, include all the verses in which the subject of female creativity in Banoo Ghasseb's personality is mentioned.

\section{Theoretical foundations of research}

Estes is one of the psychotherapists who has a special view of women in her opinions. With the aim of identifying women in different societies, she has designed and formulated a theory that describes the process of achieving female self-fulfillment and individuality. Estes intends to paint a feminine identity independent of what men have so far explained, and to encourage and expose homosexuals to reconsider their identity and personality. In her view, women will be able to make fundamental changes at the intellectual and behavioral level by standing up to the issues they have faced so far. "The ability to withstand what we see enables women to return to their deepest nature and live there fully with all their thoughts, feelings and actions." (Estes, 2004: 68-67) The most important concept proposed in Estes' theory is the archetype of the savage woman, which shows the soul of a woman and the real experience belongs to all women and is closely related to instinct and body (Shelby, 2018: 48) and is a symbol of the first maternal lineage and includes the moments that we experience and the desire to continue this experience creates a sense of surprise and amazement in us. (Estes, 1383: 8) Whenever women rediscover this archetype and become acquainted with its empowering aspects, they try their best to preserve and guard it; Because with him, their creative life flourishes and the quality of their relationships finds meaning, depth and health, and they are no longer the target of others' aggression, and according to the laws of nature, they enjoy the gift of growing up with men and being successful. To be. The savage woman gives women knowledge that affects all aspects of their lives. (Ibid: 10) In this theory, the word savage 
does not mean that this feminine power is uncontrollable, but it means not being discovered, being vague and living naturally. Realizing women in their capacities is of particular importance in this theory. This archetype is present in the body of all women and is beyond geographical, temporal, spatial, etc. borders. From Campbell's point of view, the wild woman is found in every culture ... What woman does not understand the characteristics of the wild woman? What woman does not want to bring the wild side of herself to life? ... She is a feminine instinct who takes effective steps for herself, her family and her wild nature at the same time. (Campbell, 2004: 1vi) Estes points to the principle that women are capable of growth and excellence even without male hegemony. The foundations of Stacey's theory make it possible for us to become acquainted with the process of individuality and the feminine endeavor to emerge from the shadows and to exist independently in society. Also, the dynamic or destructive role of men in achieving this important goal is revealed.

\section{Research background}

So far, no research has been conducted on the personality of Banu Ghasseb with an approach to the theory of creative women from Estes. Therefore, the present article addresses this issue for the first time in order to examine new dimensions of this woman's personality that have not been mentioned much in other studies. However, in several studies, some aspects of the personality of this heroine have been addressed. Karachi (2002) in an article introduces Banu Ghasseb and explains the change of gender role and his stereotypical approaches in a general and superficial way. From the author's point of view, although the story has a sexist structure, the narrator tries to describe the woman's attempt to regain her identity. Bahrami-Rahnama and Tavousi (2013) in an article have analyzed the psychoanalysis of Banoo Ghasseb's character based on the views of Freud and Jung and have come to the conclusion that this epic character has an authoritarian type and has several complexes such as: castration, Inferiority is the result of sexual inequality and subjugation and benefits from defense mechanisms such as sublimation, repression and denial. يرد. In another article, these authors (2015) have criticized the archetype of BanoGsesnameh. The results of the research show that Banu Ghasseb is a model of a mother's face that goes through many stages and obstacles to achieve individuality. He fights the shadows within himself in the form of nagging and fighting against the Iranian suitors in order to achieve self-discovery and personality integration. In their article, Sattari et al. (2015) have criticized the mythology and psychology of the position of women in Banogshsbnameh. From the authors' point of view, despite seeing signs of patriarchal culture in this system, these signs have faded in the face of the dominance of patriarchal culture and populist discourse has replaced matriarchy. Estaji and Sadeghi Manesh (2016) in their articles on the dispute over the acquisition of women in Banoushsbnameh have considered it as an arena for proving the needlessness and freedom of women and their ability to keep up with men. In their article, the guest friend Kotler and Fakhraslam (1396) have briefly and briefly mentioned the influence of patriarchal culture in the process of choosing a wife and her efforts to prevent marriage.

\section{The main discussion}


In a patriarchal atmosphere, Banugshsabnameh deals with the heroic character of a woman, which in this regard is a kind of violation of the literary and cultural norms of the time. The narrator of the story, instead of dealing with Yalan and the male heroes, talks about a powerful and majestic woman who subdues men in war and bravery. The patriarchal culture was so strong in the society at the time of composing the poem that the narrator likened Banu Ghasseb to men in describing his merits. In other words, the poet of the poem, in order to identify Banoo Ghasseb, compares him with the masculine gender and describes him within the framework of masculine norms:

Wherever they were, they decided to hunt

Chou men to be boiled in time

Yel Pahlavan famous lady

You hid your head and hair

(Banoosheshnameh, 2003: 56)

Because he was not like himself

Warrior and swordsman in battle

She did not look like her husband

No one should die in the field of men

(Ibid: 106)

From Rome and from China and from Turkey and Tatar

You went to the ship with him

Every time you ask him

(Same: 113)

In this system, Banoo Ghasseb, by discovering and strengthening her strengths, has tried to appear as a worthy person in a patriarchal society, and with the emergence of various arts, not only to prove her merits, but also to cause dynamic change in men. And determine a policy for them. In support of this claim, one person tells Banu Ghasseb that he has given him a new life by killing his enemies, or that the King of India considers his marriage and spiritual union with this woman to be his life-giving motivator:

One of my enemies was Sorkhab Nam

I was at war day and night

I left the ship out of grief

That you were the king of jinns 
I missed this world ...

I will sacrifice my life

(Ibid: 58)

Choo Banu Kani Banu Khan Ma

Rise from him our souls

(Same: 107)

A look at Banougsheshb's intellectual and behavioral behavior shows that this woman has outstanding signs of creativity and inner prosperity that make her personality special and make her a model of a successful woman. The most important examples and components of the creative women's model that have been depicted in Banoush Ghasseb's personality are examined and explored in this section.

\section{Independent female personality and struggle against male monophonic culture}

One of the main characteristics of creative women is that they believe in their abilities and strive to make their identity independent. Thus, while denying the patriarchal culture that governs society and separating themselves from the dominance of this onedimensional discourse, they try to make their feminine voice, which has so far been in the shadows, heard and expressed by others. "The dominance of men in society leads to the abandonment of femininity. "The privileges of being a man have disrupted the mental development of women, and for this reason, the role of women is considered an abominable role." (Adler, 1379: 89-88) Naturally in such circumstances, women become a static and inefficient element and their biological and personality conditions are seriously damaged.

Banoo Ghasseb is one of the women who has been present in a patriarchal society and has grown up with the components of this discourse. However, the expanding elements of populist discourse have not been able to completely remove her from her feminine nature, desires, aspirations and instincts, and make her a submissive being with a rigid intellectual and behavioral rigidity. Relying on her gender, the Turkish hero challenges her temper and speaks of her physical superiority over her. By using the phrase "kissing a Turkish warrior on a horseshoe", Banu Ghasseb symbolically and ironically demands the absolute obedience of the male to the female, which is contrary to the common gender norms of the time. He will refrain from humiliating her on the condition that Yale Tarktbar do so. The words that Banu Ghasseb utters and addresses the other person are a creative reaction of women to traditional and patriarchal societies that define and explain female identity in the context of a masculine model. Banu Ghasseb expresses her suppressed anger against this discourse with a superior and higher position than Tamratash and says: 
You are lucky to be here

I call that girl Rustam Zal

Chu was his gem, my gem

I got that you are a white demon

Unless you hear me

Give me a kiss on my ankle

They will not return

Forouzandeh in the tower, because Akhtarm

I serve any server in the world

My wife has a horn on your ground ...

Get off the mountain

You bite me away from you

(Banoosheshnameh, 2003: 70-69)

For Stess, the feminine instinctual nature has been rebuilt and rebuilt due to the rule of patriarchy. (Estes, 2004: 4-3) Women have grown up in an environment that has always been known as the second sex and men have believed in the superior sex and themselves as the second sex. As a result, their identities and personalities have become independent and dependent on the presence of men. In the meantime, the existence of some authoritarian and monolithic men has vulgarized potential female values and abilities and prevented the emergence and crystallization of their desirable characteristics.

Examination of Banoughasseb's verbal and behavioral reactions shows that she seeks to destroy the feminine instinctual nature formed by the patriarchal culture and has changed her identity with a protest and identity-seeking look. Banoo Ghasseb's meeting with Rostam on the battlefield on a symbolic and allegorical level is the woman's struggle to continue her feminine freedom and independence. Rostam covered his face and approached Banoogshsab anonymously. Rostam (an unknown person) as a symbolic representative of the patriarchal discourse asks her to surrender and declare her citizenship (shaping a female identity based on male will), but Banu Goshsab's reaction to this demand is aggressive and a trace of Stasis and passivity are not seen in it. Believing in his warlike abilities, he attacks Rustam (an example of a patriarchal monolithic culture) to defend his identity and rights, which have been endangered and threatened. Instead of adopting a defense mechanism, Banu Ghasseb tries to go against the threat to her freedom and defend her rights.

The lady said, "O demon." 
Let's go and fight

Say this and throw your hand on the spear

He came from the heart of Rustam

Rustam knew that he was rebellious

To the fork and arm of the tongue

How long will we delay in this plain?

You said that the drunken elephant was upset ...

Be afraid of both feet of the opponent

Which is like fire in war

(Banoosheshnameh, 2003: 72-71)

Banoo Ghasseb's non-submission and stagnation in the face of Tamrtash's request underscores the importance of the issue of personality independence and the value of freedom in Banoo Ghasseb's view. Of course, the two categories of "identity and freedom" (in other words, "name and stigma") are one of the most important value concepts in the world of epics, and heroes show resistance to any anti-sport to maintain it. But what matters in connection with Banu Ghasseb is a category beyond the defense of mere heroic values. She reacts to the patriarchal discourse that calls for her sexual subjugation in order to make her feminine voice heard in the midst of seemingly pluralistic voices, but within a single masculine voice. An instrumental view of women is one of the negative components of patriarchal discourse. Thus, Banu Gashsab's attack on Tamratash and the beheading of the Turanian warrior was a reaction to defend the epic name and stigma (general motive) and to preserve women's independence (personal motive).

My name is Tamratash Chinese

Be submissive to me because you are submissive

Otherwise, I will start working

I was shocked by this statement of Bano Goshsab

He pulled his head out of his pocket

More than Afrasiabam lineage

With the pride of your slave

Do not be sad, Negar

ز جا جشت آذركثنب ... - م

Propósitos y Representaciones

Mar. 2021, Vol. 9, SPE(2), e1030

http://dx.doi.org/10.20511/pyr2021.v9nSPE2.1030 
Cut from head to toe

(Same: 102-101)

When Tamratash (an objective example of people-centered culture) was killed by Banu Gashsab (an objective example of a woman-centered discourse), Tamratash Turani's troops were terrified and declared obedience and servitude to Banu Ghasseb. At the indepth level, this response can be seen as respect for the demands of identity-seeking and independence-seeking women, along with a fear of patriarchal discourse. This woman's competence in the field of warfare and the objective and practical proof of her power to the male group cause them to accept the identity of this woman and consider themselves subordinate to her. In other words, these actions and reactions at the lower levels show that women must strive effectively and positively to free themselves from the domination of patriarchal discourse and achieve an independent identity, and not be static and passive.

The role of the savage woman in pushing each individual towards individuality takes place through struggles that ultimately cause women to re-evaluate everything they thought they knew well. In these situations, women do not think only of themselves, but begin to become aware of phenomena other than themselves, and finally, come to the conclusion of who they are and what their individual values are. What are their ideals? (Shelby, 2018: 56) In other words, women, by discovering this archetype within themselves, reach a level of understanding and cognition that they have previously been deprived of. Naturally, the male community, seeing the dynamic and regular actions of women, respects and recognizes their wishes.

Abba he was a proud three-rounder

They saw that roaring lion

All three of his swords trembled

Zanhar was told that we were slaves

Who were with their boils and torches

Let their hands weaken and become ingots

They cut off the sweet soul of hope

We have thrown our heads at the feet

(Banoosheshnameh, 2003: 102)

One of the issues that Estes raises in relation to barriers to women's creative development is the negative role of men in the process of flourishing. Male power pursues other goals at the cost of sacrificing women's wildlife. When the male force becomes a threat, the female loses confidence in her decisions. When the masculine force within the woman becomes involved in a kind of negative psychological complex, the woman's productivity and performance decrease. (Estes, 1383: 434) A look at masculine actions in the system 
of Banogshsabnameh shows that many men They do not have a proper and accurate knowledge of the capacities of women in various fields, and based on the presupposition that emerges from the patriarchal culture, they consider this gender weak and expect pure submission and obedience. In such an atmosphere, Banu Ghasseb reacts violently and electrically in order to undermine the foundations of this attitude and to launch a new design based on the merits of the female sex and into the wild. And allow her noble femininity to appear and manifest. The primary and superficial result of this reaction is the stretching of the Turanian turret and, in fact, the disappearance of the male-dominated attitude towards women. Tamrtash calls himself a lion (symbol of strength) and Banoogshsab a grave (symbol of weakness and submission) to show the gender confrontation, a confrontation that reveals the one-dimensionality of the centrality of men. A discourse that describes women as possessed, defeated, and a sexual tool for satisfying masculine needs.

That's what the famous tour Kai said

Where is the lion afraid of the grave?

(Banoosheshnameh, 2003: 98)

Tell me, O girl of Pilten

I came to Kane from the king's door

You were shocked to meet him

I came to capture you

Now, oh my gosh

That though round and letter

Be submissive to me because you are submissive

Otherwise, I will start working

In a way, stealing my heart from my hand

Now I love the face of the moon

He bought a jewel

I bring it to Khosravani Sarir ...

Do not disturb this temperament of mine

Don't judge the light men ...

With the pride of your slave

Do not be sad, Negar 
(Ibid: 101)

In situations where patriarchal discourse prevails, creative women must believe that when they want to be themselves, there is a possibility of rejection by the dominant cultural group, and that submitting to the demands of others separates them from their true selves. . This is a torturous tension that must be endured, but choosing it is the right and clear way. (Estes, 1383: 111) Therefore, they must decide to choose their personal and identity independence with all the difficulties or to submit to the demands of masculine discourse and reduce the pressures.

Self-sufficient and creative women try to take the first step and, relying on their abilities, get rid of the cocoon of subjugation and citizenship. The ladybug did the same. As an independent woman with a creative personality, she tries to overcome the obstacles that men put in her way and overcome her identity maturity. Rostam (who can be considered a symbol of old age and guidance) talks about the dangers that patriarchal culture poses to Banu Ghasseb in order to determine the way forward for his daughter. With the presumption that she will experience many tensions, Banu Ghasseb welcomes the danger and faces many challenges. Rostam's conversation with his daughter is an objective example of this. He speaks of the dangers of Banu Ghasseb's trip to India, but this woman, relying on her spiritual and divine strength, as well as believing in her physical and fighting abilities, gives her father a hope that she will never give in to men's desires. And will remove their barriers to achieving personal and identity independence.

I am afraid of the bright moon

One cable should be adorned

Laugh, lady, you hero

If he is a friend, God bless him

Do not be one of them

If he took you to India

From us, the fog of Zaboli ...

Think of the enlightened traveler ...

Increasing knowledge, force and force

I do not know anyone from India who died

(Same: 110)

In India, Banu Ghasseb fights all her suitors. By doing this, an important concept is represented and explained at the symbolic level. In other words, Banu Goshsab's harsh and negative reaction to the men's request (to take possession of the woman and become her owner), shows the hero's efforts to maintain his independence. He does not accept 
being under the masculine framework and tries to follow the social tradition that serves the goals of men and keeps women away from the savage and noble nature they have and the possibility of flourishing from them. Stands, show a favorable reaction. As the leader of her time, Banu Ghasseb has outstanding features such as: tact, warlikeness, power of thought, decision-making, etc., which have given her social status. Naturally, giving in to the demands of Indian suitors (Jaipur, Chipal and Rai) will take him away from the full realization of his identity-seeking goals. In this respect, she removes the kings of India from the battlefield in order to somehow protest against the ownership and instrumental approach of the patriarchal discourse towards women. In fact, Banu Ghasseb has removed the obstacles to her prosperity.

The lady suffered in Jaipur

Go throw a spear at Parnahib

He grabbed Chipal by the fork

Zayn took him to his death

One was killed and the other was killed

Come to fight that famous

It became the body of the soul and the foot of the rival

He grabbed her belt and squeezed it

Throw his food to the battlefield

When he saw that, he sat down

(Same: 113)

\section{Manifestation of love as a fluid flow in life}

Estes believes that in order for the emergence, growth and maintenance of useful love in a person, there is a need to go through several stages, which are: discovering the existence of another person as a kind of spiritual treasure. Then comes the chase phase, when it is full of hope and fear for both of you. Next, it is time to untie the knots and understand the aspects of life and the compassion needed to do the job. Next, it is time to rest and trust, and the ability to relax in the presence of another and share in the future dreams and sorrows of the past, then, using the heart to sing the anthem of new life and finally, the unification of the soul And tone. (Estes, 1383: 183) On this basis, if the mentioned process is not considered during lovemaking between the two sexes, the negative reactions of one of the parties to the relationship will be shown and the nature of love that will be identifiable and perfect. $\neg$ It is good, it hurts.

Although Banu Ghasseb loves his family and accepts them as role models (Zal and Rostam) and companions (Faramarz) in life, but outside this circle, he takes harsh 
attitudes towards others, especially men. مكى كند. This is Banu Ghasseb's negative reaction to his wife, Guo. He has no spiritual or heart connection with Guo, and on the advice of his father, the elders, and through a hierarchical hierarchy based on the principle of physical superiority, he was forced to marry this person. Therefore, he does not have an emotional and romantic mentality from Gio and does not consider him a spiritual treasure. In such a situation, there is no hope, motivation or attraction for Banu Ghasseb based on which she can recognize, analyze and solve her mental knots. As a result, this hope becomes a kind of fear in this woman's mind, and eventually, due to not being addressed, it turns into a blind knot. Naturally, in such circumstances, there is no trust or peace in the marital relationship. He has been forced to associate with Gio, and this has been imposed on him by the monolithic and one-dimensional patriarchal tradition and culture. In this culture, the pattern of "love" has little use; Because "patriarchal culture has always ... forbidden women from being in love. "In the eyes of these women, love is giving individuality instead of strengthening it." (Faridan, 1394: 312) Therefore, with this premise, Bano Goshsab ties Gio's hands and throws the hero under the bed to show his protest against the masculine rules of society with this symbolic act. He sees no union between himself and Gio; Their bond is not based on the voice of the heart and the involvement of emotion.

Estes believes that "making love means uniting the body and soul, soul and matter, and being in each other, and this is a description of a romantic relationship that will last." "It is an immortal relationship of soul to soul that we cannot describe, but we experience deeply." (Estes, 1383: 223) However, the relationship between Banu Gashbeh and Gio is formed by coercion and a rule that the patriarchal discourse has imposed on this woman without considering the desires of the female sex. As a result, the process that Estes is talking about does not take place in the marital relationship between the two heroes, and the realization of the perfectionist goals of lovemaking does not appear as it should and perhaps does. Although he expresses his dissatisfaction with this culture, in the end, Rostam tries to moderate this belief in Banu Ghasseb's view by using his spiritual influence and the application of soft hegemony of masculine power, and the contradiction that contradicts the patriarchal discourse. This woman has created, destroyed and "returned things to goodness" (Safa, 1378: 303) and provide and explain a redefinition of the category of marriage and marriage.

However, in most of the stories, the concept of love is depicted as one of the important events in the narrative, and the heroes express new dimensions of their personality with love, and "one of the foundations of happiness and success in The end of stories and legends is the integration of different aspects of the personality of the prince and princess and their marriage "(Bettelheim, 1392: 183), but the marital relationship between Bano Goshsab and Gio is still one of the benefits of the element of love and affection. It remains productive and its level is reduced to performing a social ritual. The story ends immediately after the marriage, and the narrator only mentions that Bijan was the result of this union. Therefore, after marrying Guo, no image of Bano Goshsab's face comes to mind. 
Let the slanderer come near them

See that the lady is sitting on the bed

Hear one moan Rostam Nahan

I also posted in the hiding place

He slandered her and untied her

"Make it with the show," he said to Lady Yale

The woman of the show has a high character

When you hear this, Lady Sarfaraz

Who sees their narrow hearts and voices

You should not wake up with him ...

That's what Kai, the world champion, said

I bent the rope with both hands

Show off the girl and the honorable Bob

If she is a woman, she will be proud of her show

Don't be shy in the language of blame ...

They sat together on the open bed

(Banoosheshnameh, 2003: 128-127)

\section{Inactivity, intransigence and trying to disrupt unfavorable situations}

Estes believes that when women agree to be the wives of a wicked and profiteering man, they choose an indirect and deviant path; Because women's instincts are not yet efficient enough to pay close attention to issues and act correctly. (Estes, 2004: 59) According to this view, women who give in to the unwarranted demands of men in accordance with the patriarchal culture, distance themselves from their creativity and originality.

There is no sign of Banu Ghasseb's inaction and weakness in most parts of Banoushsabeh. Not only does he not traditionally consider himself a subject of the men of the age, but in some cases, he assumes the role of their guide and guide and corrects their intellectual errors. His reactions to this epic work have often been dynamic and creative. He has an active and unyielding spirit. Breaking the norms defined by men and trying to tear down the conservative cocoon that patriarchal discourse has woven around women's personalities and identities, as well as discovering new and unknown dimensions of life that lead to cognitive and insightful changes in Banu Ghasseb. $\neg$ Yes, it is obvious in this system. 
One of these examples is the woman's lack of attention to Zal Zar's advice. Although Banu Ghasseb is emphasized not to be present in the hunting grounds due to her border with the Turanians, but she does not follow this advice and to gain more knowledge of the environment and Discovering new dimensions of life, hunting at the borders. "Creating a relationship with wildlife is an essential part of the growth and development of women's individuality. "For this, the woman must walk in the dark, but at the same time she must not be irreparably trapped, captured and killed on the way to or from there." (Ibid: 56) On this basis, Banu Ghasseb believes in his physical abilities and heroism to such an extent that he welcomes dangers. Zal is worried about hearing this and advises Rustam to find a way to ward off this abnormality. Although Zal and Rostam are not evil men, they believe in a patriarchal discourse and act on its components. At the symbolic level, Zal's verbal action (Banoo Ghasseb does not go to the hunting ground), Banoo Ghasseb's reaction (presence in Nakhchirgah without permission) and Rostam's tactic (intimidating Bano Goshsab under the cover of Turanians) represent the process of conflict between the interests of patriarchal culture and women-centered discourse in society. By attending Nakhchirgah, Banugshsab tries to increase her level of knowledge and insight and discover new epistemological boundaries, but the reaction of the patriarchal discourse to this movement is negative and deterrent. In other words, Zal's request is static and negative, but Banu Gashsab's action is passive and dynamic.

You hunted there every day

He gave them a lot of advice

Skip the plains of Raghoo plain

That is where the Turanians pass

Make way for the land of the way

The absence of these words was heartwarming

Their plain was there all day

Zal's heart became golden from this restlessness

That's the light of my eyes on the door

Jump across the plain

All famous and all spearmen ...

Do not ignore my advice

They thought this was a good thing

Khorramabad was their vote

(Banoosheshnameh, 2003: 63-62) 
War and escape and surprise is a term and a spiritual movement that a woman uses to regain control over her life. In these wars and escapes, the soul tries to avoid being killed. This soul is no longer naive and raw and has become shrewd and alert. In the real world, we all see women plotting to flee and seeking help from within. Sometimes it is this kind of horrible threat from the abuser that makes the woman transform from an obedient and lovable creature into a person with the keen eyes of an observer. (Estes, 1383: 77-76)

When confronted with an objective threat in the real world, Banu Ghasseb also prepares her inner forces to fight the unknown attacker. Banu Ghasseb is the "human and earthly incarnation of the female god of the mythical warrior god" (Aidenloo, 1387: 16) and is always ready to fight with strangers. In order to prevent Banoosh Ghasseb from being present in the hunting grounds, Rostam disguises himself as an unknown person and stands in the way of his daughter and challenges her to fight. Unaware of the truth of the matter, Banu Ghasseb immediately feels threatened and becomes defensive. By plotting to attack the attacker, he conveys the message to the unknown that he does not intend to obey. He never gives up and in the most critical situation, he still tries to defeat the enemy. Rustam pretends that as a wicked man, he intends to rape and capture Bano Goshsab. This woman's reaction is immediate and violent. He does not intend to bow down and become a victim, and "plots to kill the aggressor" (ibid .: 77) in order to achieve his goal. The reporter of Banoo Ghasbnameh has explained this confrontation and war in the following verses:

Say this and the strong head

One razor in hand like a drunken elephant

Choo Rostam gave such a robbery

To the forearm of the ladybug razor

Break the rope by force

He drove his father's sword

He ran his hand and forearm towards the razor

Holding a razor blade

(Banoosheshnameh, 2003: 84)

\section{Benefit from the power of creativity}

Estes believes that creativity is a woman's most valuable asset; Because it includes different psychological, spiritual, intellectual, emotional and economic levels. (Estes, 1383: 411) In his view, "Creative power originates from the soul of women and is reflected in their lives. Every human being and school defines creativity in its own way. "Some define it in beliefs and some in practice." (Ibid: 409) Thus, two representations of creativity are conceivable: 1 . Abstract and internal; 2. Objective and external. In other 
words, creativity is understood both on a spiritual level and leaves desirable effects that the creative person and those around him, indirectly realize the benefits of this power, and also has external examples that can be directly Is an observation.

There are examples of both types of creativity in the story of Banu Gossabnameh. Needlework and support for this practice and its spread in society, which has led to the emergence of art in the cultural context of a specific population group, is one of the objective manifestations of creativity. According to the narrator of Banoogshsbnameh, this woman created the art of needlework for the first time and painted interesting patterns and drawings on fabric and so on.

They came to the porch at night and sometimes

So then the lady to the fog

The lady is left with that relic

The sun and the moon shone brightly

Do not paint with a needle

Which is made of needlework

(Banoosheshnameh, 2003: 59)

At the abstract level, creativity has brought about fundamental changes in Banu Ghasseb's personality, making her a prominent and unique woman in her time. So that in the culture of Persian literature, which is a branch of the patriarchal discourse of Iranian society, a system has been dedicated to recording and representing the thought, behavior and speech of this woman. The composition of this poem in a situation where the literary community of that time did not involve women in their works or a ghostly presence And they drew a margin from them, which is interesting and shows valuable points. Naturally, a woman like Bano Goshsab, who has excelled in various arts, has become worthy of mana in the field of epic literature. Literature that is based on name and stigma and the heroes do not give up any action to provide these elements. Lady Goshsab has also succeeded in doing this important thing and finally, as an authoritarian woman "who loves to give orders and make laws" (Oldham and Morris, 2006: 484), while arousing the admiration of the heroes of her time, attracted the attention of others. Which has attracted these heroes to the field of writing.

With regard to these explanations, we read in a part of Banooshsabeh's poem that when Banoogshsab and Faramarz are besieged by Turanian troops, the reaction of this brother and sister is interesting. According to the norms defined by patriarchal discourse, women in such situations rely on men and react passively, and men appear as saviors, but here the lady breaks all existing norms. Zand tries to persuade Faramarz to resist and eliminate the unfavorable situation in which they find themselves, while maintaining vigilance and providing a correct and logical analysis of the environment. The contrast between the 
reaction of this brother and sister introduces the audience to the self-reliant spirits and characteristics of Bano Ghasseb. By determining the necessary strategies, he prepares Faramarz mentally and physically to fight the Turanian enemy and gives him hope and motivation. Banu Ghasseb has a self-sufficient personality and knows well what decisions should be made in critical situations. Hence, he determines the general line and Faramarz, under the command of his sister, goes to the battlefield and fights the enemy.

So said the lady who Turan Sepah

But you take the sorrow away from your heart

From this king of the army you think nothing

If they resent, we will do it

They pulled on the tight squares

Report the inner highway ...

Surrender to the death of their general

I have ignored several turns

To regret their coming

They rode on the determination of war

(Banoosheshnameh, 2003: 88)

As a dynamic woman free from the stereotypes of tradition, culture and society, Banu Ghasseb has influenced many men and drawn their attention to the fact that women are also able to acquire human education if the necessary conditions are provided. And in the field of self-knowledge they achieve higher degrees than men. By quoting several anecdotes about this woman, the reporter of Banooshsabnameh tries to induce the important fact that the women of a society, if their abilities flourish, move alongside the men and by being present in different sectors, make an impact. They have to. What reinforces this view are the conscious confrontations created by the narrator at various events. By depicting the conditions of men (Faramarz) vis--نانvis women (Banu Gashsab), while revealing the intellectual and personality perfection of women, he has challenged the dominant view of men over women and, in contrast, has proposed a humane attitude regardless of gender boundaries. . The point that can be achieved in the above verses is that the creative presence of women in various levels of society will make them role models for men and the necessary grounds for society to move towards perfection will be accelerated. . Banogshsab had grown so much in warfare and heroism that the famous Yalans of his time such as: Zal, Rostam, Faramarz, Gio, etc. were praised by him. Banoo Ghasseb's creations challenge the audience's mental imagery and give intellectual and cognitive development to the target group, especially women, by proposing new thought patterns. Of course, Banu Ghasseb has not been a pioneer in this 
field and many heroes before her have shown their creativity, but what adds to the value of Bano Gosheshb is her work as a woman.

\section{Conclusion}

Banu Ghasseb does not have a passive and static character and plays an obvious role in the epic. He shows traces of independence and identity, and although under the pressures of patriarchal discourse (Rostam's advice to him), he agrees to marry Gio in order to follow the norms defined by men. He does not step in, but he never gives up trying to represent his identity, and in this regard, he forces some men to obey and accept him. The poetess of Banooshsabnameh cultivates the character of Faramarz alongside Banoogshasb in order to strengthen the feminist thought at the level of depth and the secondary layer; Because Faramarz is inferior to his sister in terms of management, personality, intelligence and fighting spirit. In most cases, instead of relying on men, Banu Ghasseb relies on her physical and mental capacities to achieve her desires and strives to achieve the desired goal. Examining the personality of this hero based on Stacey's creative theory shows that she has an independent female personality and tries to break the order arising from the culture of male monologue and to disturb undesirable situations. By creating cognitive and exploratory experiences, he has accepted love of the family as a fluid flow in life, but due to the dominance of patriarchal discourse, shows a negative reaction to falling in love with another man as a wife; Because in this discourse, women are forbidden from making love or a special kind of affection that is according to the will of men is recommended. Utilizing her creativity, Banu Ghasseb has overcome many biological barriers and achieved unparalleled power among the heroes of epic texts. Examples of this creativity fall into two categories: objective and tangible (invention of needlework) and abstract and spiritual (appropriate presence with men in matters of warfare and heroism). Represented The Characteristics of Banu Goshsab In Banu Gshasbna's system, it is important to note the extent to which women are able to grow and prosper in human societies. Banu Ghasseb is a personality that can be cited to prove that men should not look at women from a superior position, and in social behaviors, what should be the principle is the quality of thought, behavior and speech. Thus, during the plot of the epic and martial events, the narrator recounts his social and cultural concerns in the lower layers of the anecdotes related to Banu Ghasseb.

\section{References}

1- Adler, Alfred, (2000), Understanding the Nature of Man, translated by Tahereh Javadsaz, Tehran: Roshd.

2- Aidenloo, Sajjad, (2008), "Pahlavan Banoo", Journal of Iranian Studies, No. 13.

3- Estaji, Ebrahim and Sadeghi-Manesh, Ali, (2016), "An Equivalent Study of the Controversy over the Possession of Women in the Two Epic Works of Banogshsabnameh and Iliad", Journal of Comparative Literature, Volume 8, Number 14. 
4. Estes, Clarissa Pincola, (1383), Women Who Run with Wolves; Myths and Stories about the Wild Woman Archetype, translated by Simin Movahed, Tehran: Peykan.

5- Oldham, John and Morris, Louise, (2006), The New Face of Personality, translated by Mehdi Qarachehdaghi, Tehran: Scientific.

6- Banooshsabnameh, (2003), Introduction and explanation and correction by Rouhangiz Karachi, Tehran: Research Institute for Humanities and Cultural Studies.

7- Bethlehem, Bruno, (2013), The Enchantment of Legends, translated by Akhtar Shariatzadeh, third edition, Tehran: Hermes.

8- Bahrami Rahnama, Khadijeh and Tavousi, Mahmoud, (2013), "Psychoanalytic Analysis of Banu Goshbeh Personality Based on Freud and Jung's Opinions", Journal of Analysis and Interpretation of Persian Language and Literature Texts, Volume 5, Number 17.

9(1394), "Archetypal Critique of the Banu Gashsabnameh System", Journal of Mystical Literature and Mythology, Volume 11, Number 40.

10- Riahi Zamin, Zahra and Jabareh Nasroo, Azim, (2011), "Mixing Myth and Epic in Another Narration of Banooshsabnameh", Journal of Literary Research, No. 18.

11- Sattari, Reza and Hassanpour Alashti, Hossein and Haghighi, Marzieh, (2015), "Mythological and Psychological Critique of the Status of Women in the Journal", Journal of Women in Culture and Art, Volume 7, Number 1 .

12- Safa, Zabihollah, (1999), Epic in Iran, Tehran: Ferdows.

13- Faridan, Betty, (2015), Women's Razuri, translated by Fatemeh Sadeghi et al., Second edition, Tehran: Contemporary View.

14- Karachi, Rouhangiz, (2002), "Lady Goshsab, the heroine of Iranian epics", Journal of Humanities, Shahid Beheshti University, No. 33.

15- Karachi, Rouhangiz and Khatibi, Abolfazl and Mazdapour, Katayoun, (2005), "Symbol of life and fertility", Book of the Month Book of Literature, No. 93.

16- Hostel Kotler, Roghayeh and Fakhraslam, Batool, (2017), "Study of lyrical components and its function in Banooshsabnameh", Journal of Persian Language and Literature, Islamic Azad University, Sanandaj Branch, Volume 9, Number 32.

17- Campbell, Joseph, (2004), The Hero With a Thousand Faces, Princeton: Princeton University Press.

18- Shelby, Stacey, (2018), Tracking the Wild Woman Archetype: A Guide to Becoming a Whole, In-divisible Woman, Asheville: Chiron Publications. 
